\title{
Severe neonatal lactic acidosis due to NFS1-ISD11 complex deficiency
}

INSERM

\section{Source}

INSERM. (1999). Orphanet: an online rare disease and orphan drug data base. Severe neonatal lactic acidosis due to NFS1-ISD11 complex deficiency. ORPHA:397593

Severe neonatal lactic acidosis due to NFS1-ISD11 complex deficiency is a rare, hereditary, mitochondrial oxidative phosphorylation disorder characterized by severe neonatal lactic acidosis and deficiency of mitochondrial complexes I, II and III. Clinical features are variable and may include hypotonia, respiratory distress with cyanosis, failure to thrive, feeding difficulties, hypoglycemia, dehydration, vomiting, seizures, and a risk of multiple organ failure. 